bioRxiv preprint doi: https://doi.org/10 1101/661587; this version posted June 12,2020 . The copyright holder for this preprint (which was not certified by peer review) is the author/funder, who has granted bioRxiv a license to display the preprint in perpetuity. It is made available under aCC-BY-NC 4.0 International license.

\title{
MOLECULAR CHARACTERIZATION OF THE STRESS NETWORK IN THE HUMAN BRAIN
} Mandy Meijer ${ }^{1,2,3}$, Arlin Keo ${ }^{1,4}$, Judith M.C. van Leeuwen ${ }^{5,6}$, Oleh Dzyubachyk ${ }^{7}$, Onno C. Meijer ${ }^{2}$,

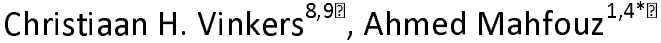

1. Leiden Computational Biology Center, Leiden University Medical Center, 2333 ZA Leiden, the Netherlands,

2. Department of Internal Medicine, Division of Endocrinology, Leiden University Medical Center, 2333 ZA Leiden, the Netherlands

3. Department of Human Genetics, Cognition and Behaviour, Donders Institute for Brain, Radboud University Medical Center,

6525 GA Nijmegen, the Netherlands

4. Delft Bioinformatics Lab, Delft University of Technology, 2628 XE Delft, the Netherlands

5. University Medical Center Utrecht, Department of Psychiatry, Utrecht, The Netherlands

6. Donders Institute for Brain, Cognition, and Behaviour, Radboud University Medical Center, Nijmegen, The Netherlands

7. Department of Radiology, Division of Medical Image Processing, Leiden University Medical Center, 2333 ZA Leiden, the

Netherlands

8. Department of Psychiatry, Amsterdam UMC (location VUmc)/GGZ InGeest, $1081 \mathrm{HV}$ Amsterdam, the Netherlands

9. Department of Anatomy and Neurosciences, Amsterdam UMC (location VUmc), 1081 HV Amsterdam, the Netherlands

${ }^{\text {G }}$ Shared last author ship

*Corresponding author

Ahmed Mahfouz

Post-adress: Einthovenweg 20, 2333ZC Leiden, The Netherlands

E-mail: a.mahfouz@lumc.nl

Telephone: +31613751240 


\section{ABSTRACT}

The biological mechanisms underlying inter-individual differences in human stress reactivity remain poorly understood. We aimed to identify the molecular underpinning of neural stress sensitivity. Linking mRNA expression data from the Allen Human Brain Atlas to task-based fMRI revealed 201 differentially expressed genes in cortex-specific brain regions differentially activated by stress in individuals with low or high stress sensitivity. These genes are associated with stress-related psychiatric disorders (e.g. schizophrenia and anxiety) and include markers for specific neuronal populations (e.g. ADCYAP1, GABRB1, SSTR1, and TNFRSF12A), neurotransmitter receptors (e.g. GRIN3A, SSTR1, GABRB1, and HTR1E), and signaling factors that interact with the corticosteroid receptor and hypothalamic-pituitary-adrenal axis (e.g. ADCYAP1, IGSF11, and PKIA). Overall, the identified genes potentially underlie altered stress reactivity in individuals at risk for psychiatric disorders and play a role in mounting an adaptive stress response, making them potentially druggable targets for stress-related diseases.

KEYWORDS: Stress reactivity, stress network, stress-related diseases, stress sensitivity, molecular correlates 


\section{INTRODUCTION}

Stress is a major risk factor for the development of a wide range of psychiatric disorders, including schizophrenia and depression. ${ }^{1}$ Inter-individual differences in how the brain responds to stress depend on intrinsic (e.g. genetic and developmental) as well as on extrinsic (e.g. hormonal) factors. ${ }^{2}$ The neural correlates underlying stress reactivity are currently a growing topic of investigation..$^{3-5} \mathrm{In}$ healthy individuals, acute stress causes a shift in neural networks by suppressing the executive control network and activating the salience network and default mode network (DMN). ${ }^{6}$ One hypothesis is that stress vulnerability is the result of maladaptive changes in the dynamic response of these neural networks, either during the acute phase, during the recovery period in the aftermath of stress, or both. ${ }^{2}$ Moreover, acute social stress deactivates the DMN in the aftermath of stress during emotion processing in healthy controls but not in siblings of schizophrenia patients who are at-risk for several psychiatric disorders., ${ }^{7,8}$ Yet, the molecular mechanisms underlying differences in brain reactivity to stress in humans remain unknown as access to the tissue of interest in humans is limited.

Nevertheless, stress-related brain regions and networks as identified by fMRI can be further characterized based on transcriptomic signatures. Mapping gene expression atlases of the healthy brain to imaging data allows the identification of the molecular mechanisms underlying imaging phenotypes. Previous studies have identified gene expression patterns associated with structural brain changes in autism spectrum disorders, Huntington's disease and the onset of schizophrenia. ${ }^{9-12}$ Similarly, mapping resting-state fMRI and connectivity data onto gene expression atlases has led to identification of molecular profiles underlying these fMRI networks. ${ }^{13-15}$

In this study, we examined the putative molecular signatures of brain regions linked to stress reactivity. We linked gene expression data from the Allen Human Brain Atlas (AHBA) to an fMRIstress network (Figure 1). In short, we found that the stress network was enriched for genes associated to specific subtypes of neurons (i.e. components of the cortical circuitry) with genetic relevance for psychiatric disorders, and for signaling factors and proteins that interact with the 
activation of the Hypothalamic-Pituitary-Adrenal axis (HPA-axis) and response to glucocorticoids.

These all constitute potential targets for directed pharmacotherapy in stress related disorders.

\section{METHODS}

\subsection{Defining the stress network}

Based on a previous study, we selected brain regions that were differentially affected by stress in individuals with high and low stress sensitivity. ${ }^{6}$ In this study, there were four experimental groups: control-no-stress ( $n=19)$, control-stress $(n=20)$, sibling-no-stress $(n=20)$ and sibling-stress $(n=19)$ (Table 1). Before scanning, participants in the stress groups underwent a Trier Social Stress Test ${ }^{16}$ and 30 minutes after the onset of the test, participants performed an emotion-processing task in the magnetic resonance imaging (MRI) scanner based on the International Affective Picture System ${ }^{17}$ during which pictures were presented that had to be rated as either neutral, positive or negative. All participants in this experiment gave written informed consent and the experiment was approved by the Utrecht Medical Center ethical review board and performed according to the guidelines for Good Clinical Practice and the declaration of Helsinki. Based on a $2 \times 2$ ANOVA (control/sibling $\times$ stress/nostress) voxel-wise analysis, several brain regions that responded differently to all pictures after acute social stress in siblings compared to healthy individuals were identified. These regions include key nodes of the DMN (posterior cingulated cortex/precuneus and medial prefrontal cortex) and salience network (anterior insula), as well as the superior temporal gyrus, middle temporal gyrus, middle cingulate gyrus, ventrolateral prefrontal cortex, precentral gyrus and cerebellar vermis (Figure 2A). We selected and present in the figures the cortex-specific brain regions for the initial analyses to prevent that our results are being driven by differences between the cortex and subcortex. Analyses on all brain regions in the stress network can be found in the supplementary text. 


\subsection{Allen Human Brain Atlas (AHBA)}

Gene expression data from six healthy brains were acquired from the AHBA. ${ }^{18}$ In this microarray dataset, probes were mapped to genes as previously described..$^{19}$ Z-scores for normalized gene expression levels from the AHBA were calculated separately for each of the six individual brains. Gene expression data were linked to an fMRI-based stress network according to the MNI coordinate system, such that samples of the AHBA exactly overlap with the corresponding fMRI voxels. For all samples in the AHBA, we determined whether they were located in the cortical stress network for all six donors separately. The gene expression levels of the AHBA samples were extracted and resulted in expression data of 19,992 genes in 111 and 1839 brain samples in- and outside the cortical stress network, respectively.

\subsection{Differential gene expression in the cortical stress network}

To identify genes differentially expressed between the cortical stress network and the rest of the cortex, we analyzed each of the six brain donors separately. Differential expression was determined for the cortical stress network altogether as one mask. For each gene, we combined effect sizes (difference in mean expression between the brain stress network and the rest of the brain) across donors using a meta-analysis approach from the 'metafor' 2.0-0 R package. In brief, a random effects model was used, taking into account the within-brain and between-brain variance, which was estimated with the Dersimonian-Laird model. Variances and confidence intervals needed for the meta-analysis were calculated using the escalc-function. Genes were considered to be differentially expressed at an $\mathrm{BH}$-adjusted $\mathrm{p}$-value $<0.05$ (Benjamini-Hochberg $(\mathrm{BH})$ correction).

We also performed analysis on the whole brain (differentially expressed genes BH-adjusted $\mathrm{p}$-value < 0.05 and $\log _{2}($ Fold Change $\left.)>|1|\right)$. Given the large difference in the transcriptional profile of the cerebellum compared to the rest of the brain ${ }^{20}$, we excluded the cerebellum from the whole brain analysis. In addition, we performed the differential expression analysis between samples inside and 
outside the stress network for each of the following brain regions separately: cerebral cortex $(C x)$, frontal gyrus $(\mathrm{FG})$, cingulate gyrus $(\mathrm{CgG})$, cerebellum $(\mathrm{Cb})$, and the hippocampal formation (HiF). Other anatomical regions contained too few samples $(<2$ in the mask) to perform the analysis on these particular structures separately.

We used a bootstrapping approach to assess the robustness of our results with respect to the imbalance between the number of AHBA samples inside and outside the cortical stress network (111 inside and 1839 outside). We randomly selected 111 samples from the whole cortex, regardless of their location inside or outside the stress network and compared gene expression profiles of these brain samples with the original set of 111 samples inside the cortical stress network. We repeated this process 1000 times to assess the reproducibility of the differentially expressed genes

\subsection{Gene Ontology (GO) enrichment analysis}

To characterize the functionality of the differentially expressed genes, a GO enrichment analysis was performed. The list of unranked differentially expressed genes was uploaded to GOrilla (Gene Ontology Enrichment Analysis and Visualization Tool). ${ }^{21}$ As a background list, the top $20 \%$ of genes with the highest expression level in the cortex was used, to correct for non-selective ontologies. GO terms were considered significant when the $\mathrm{p}$-values $<0.001$ (Fisher's exact test) after BH-correction.

\subsection{Cell type enrichment analysis}

We assessed whether the differentially expressed genes were enriched for cell type markers. ${ }^{22}$ Genes with a 20-fold higher expression in neurons (628 marker genes), oligodendrocytes (186 marker genes), astrocytes (332 marker genes), microglia (520 marker genes) and endothelial cells (456 marker genes) were considered to be markers for that cell type. Since most of our AHBA samples were located inside the cortex, we used a set of brain-region-specific markers and focused on 18 
cortical cell types. ${ }^{23}$ Details on markers can be found on https://pavlab.msl.ubc.ca/data-andsupplementary-information/supplement-to-mancarci-et-al-neuroexpresso. Finally, to assess which neuronal cell types might be involved in stress sensitivity, single cell RNA sequencing data of the middle temporal gyrus of the human neocortex from the Allen Brain Institute ${ }^{24}$ (http://celltypes.brain-map.org/rnaseq/human) were used. The sum of the $\log _{10}$ values of the counts per differentially expressed gene were calculated for each cell cluster separately.

\subsection{Enrichment analysis of disease-associated genes}

To assess whether the differentially expressed genes are associated to stress-related psychiatric disorders, a disease-associated gene enrichment analysis was performed based on existing GenomeWide Association Studies (GWAS) including schizophrenia ${ }^{25,26}$, Bipolar Disorder ${ }^{31}$, and Major Depressive Disorder ${ }^{32}$, and stress-related diseases such as Post-Traumatic Stress Disorder, as well as non-stress-related diseases (e.g. Huntington and osteoporosis) based on disease gene sets from DisGeNET ${ }^{27}$. As non-disease control conditions, genes associated to height and waste-hip ratio were included in the analyis. ${ }^{28,29}$ The schizophrenia, MDD and BP GWAS loci were considered to be associated if they reached genome-wide significance of $p<5 * 10^{-8}$. Intersections of loci based on GENCODE with UCSC hg19/NCBI build 37 position were used to map loci to risk genes by the authors

of the GWAS. ${ }^{25,30,31}$ These annotations were used for the enrichment analyses. All genes assessed in the AHBA that were not associated to a disease or trait were used as background test in the Fishertest. FDR-correction was applied over the amount of enrichment tests.

To assess the enrichment of disease-related gene sets in intercellular signaling genes, neuropeptides and receptor genes were selected from the differentially expressed genes. Odds ratios (ORs) were calculated for the set of neuropeptides and receptors for each disease as a measurement of effect size, (i.e. the increased chance of a peptide or receptor being present in the set of differentially expressed genes). For this, the number of receptors found within the trait was compared to all the 
receptors that were measured in the AHBA (1203 receptors), based on the gene annotation of the AHBA. Gene names that included the word 'receptor' were selected and this list was manually verified whether the gene was a receptor or a modulator. The ORs for the neuropeptides were calculated in the same way, based on a list of neuropeptides available from NeuroPep. ${ }^{32}$

\subsection{Mineralocorticoid and glucocorticoid DNA binding loci}

MR and GR DNA binding loci under stress in the rat hippocampus were previously assessed. ${ }^{33}$ We identified sets of genes with GR-specific, MR-specific and GR-MR-overlapping DNA binding loci, i.e. potential target genes. To predict glucocorticoid sensitivity of our differentially expressed genes, we assessed whether these sets of targets were enriched among the differentially expressed genes.

\subsection{Enrichment statistics for GO, cell type, disease-associated genes and receptor binding}

Enrichments were assessed based on Fisher's Exact Tests and odds ratios (ORs) were calculated as a measurement of effect size for the enrichments. An OR of 1 indicates no effects, whereas an $O R>1$ and $0<O R<1$ reflects enrichment and depletion, respectively. All $p$-values were corrected for multiple testing using Benjamini-Hochberg method and a BH corrected $\mathrm{p}$-value $<0.05$ was considered to be significant, unless stated otherwise.

\section{RESULTS}

\subsection{Differentially expressed genes in the stress network}

We identified the gene expression signatures of the cortical stress network with altered stressinduced activity by determining which genes are differentially expressed in the stress network compared to the rest of the cortex. Using a meta-analysis approach to combine results across all 
donors of the AHBA $(n=6)$, we identified 201 differentially expressed genes (BH-adjusted $p<0.05$, Figure 2B; Table S1). Among those genes, 177 were higher expressed, while the other 24 genes were lower expressed in the cortical stress network compared to the rest of the cortex. Using a bootstrapping approach (see 2.3), we found the identified set of genes to be highly robust to the imbalance between the number of AHBA samples inside and outside the stress network (in $83 \%$ of our 1000 iterations, only genes out of our initial 201 differentially expressed gene list were found).

We also identified the gene expression signatures of the stress network with altered stress-induced activity by determining which genes are differentially expressed in the stress network compared to the rest of the brain minus the cerebellum. Using the same meta-analysis approach, we identified 261 differentially expressed genes (BH-adjusted $p<0.05$ and $\log _{2}$ (fold-change) $>|1|$ ). A full description of the results, including tables and figures, can be found in the supplementary text. However, due to the higher representation of cerebral cortex samples in the brain regions vulnerable to stress (109 out of $127 ; 91 \%)$ compared to the rest of the brain minus the cerebellum $(1,950$ out of $3,225 ; 60 \%)$, differentially expressed genes in the whole brain stress network were also differentially expressed between cortical and non-cortical samples (222 out of 261 genes were also differentially expressed in the top $10 \%$ difference between cortex and non-cortex, $\mathrm{p}<0.00001)$. Therefore, we chose to focus on the cortex-specific stress network.

The differentially expressed genes in the cortical stress network generally showed high expression values in the cortex but not the hippocampus, and mostly low expression levels in non-cortical areas (Figure 2D). The two most differentially expressed genes in the stress-specific cortical regions are Tumor necrosis factor receptor superfamily member 12A (TNFRSF12A) (BH-adjusted $\mathrm{p}$-value $=0.006$, $\left.\log _{2}(F C)=-0.24\right)$ and Exosome Component 6 Pseudogene (LOC392145) (BH-adjusted $p$-value $=0.009$, $\left.\log _{2}(F C)=0.38\right) . T N F R S F 12 A$ may module cellular adhesion to matrix proteins, whereas $L O C 392145$ is an mRNA transport regulator. 


\subsection{Functionality and cell-type specificity of differentially expressed genes in the stress network}

A GO term enrichment analysis was performed to assess whether the differentially expressed genes in the stress network are enriched for specific functions. The differentially expressed genes were enriched for GO terms involved in neuronal development and neurogenesis, synaptic signal transmission, and glutamate receptor signaling (Figure 3A and Table S1). Genes involved in most processes based on $\mathrm{GO}$ terms (at least assigned to five out of ten GO terms) include SHANK, GRIN3A, CNTN4 and ADCYAP1. Enrichment analysis for cellular components indicated that the proteins coded by the differentially expressed genes were mainly found at the synapse, reflecting both the high expression of the genes in the synapse-dense cerebral cortex, and a potential role for synaptic proteins as determinants for the differential activation.

Next, we identified the specific cell types underlying the differential gene expression levels in the cortical stress network using enrichment analysis of cortical cell-type markers. ${ }^{22}$ Enrichment was found for neuronal cell markers (BH-adjusted $\mathrm{p}=5^{*} 10^{-5}$ ), including ADCYAP1, DPYSL3, INSM1, PKIA, SSTR1, NOL4, BAIAP3, KCNB2, FAM65B, ABLIM3, TEKT2, SHANK1, DACT1, PCBP3, SCN3B, LMO3, CA10, LRRTM4, SYT16, GPRIN1, TMEM200A, LRRC3B, GRIN3A, and PNCK. However, no specific subtype of neuron was in particular enriched. Enrichment was also found for astrocytes (ATP2B4, PTCH1, FABP7, IGSF11, KCNN3, GRM3, GABRB1, PTX3, BH-adjusted $\mathrm{p}=0.024)$. The list of differentially expressed genes included a few microglia (TMEM52, F13A1, MSH5, ARHGAP4, NOD2, and TNFRSF12A), endothelial cell (LAMA1, LAMB1, C1orf115, DOK4, and MICB), and oligodendrocyte markers (EFNB3 and TYRO3), although not significantly enriched ( $\mathrm{BH}$-adjusted $\mathrm{p}=0.924)$. Moreover, we found that neuronal markers showed a partially overlapping distribution in a t-Distributed Stochastic Neighbor Embedding (t-SNE) map of all genes across the whole brain as the differentially expressed genes in, indicating that neuronal markers and the differentially expressed genes show the same expression patterns across cortical areas (Figure 3B) and thus differential activity may depend on neuronal gene expression. 
Using a human-specific single cell RNA-sequencing data of the medio-temporal gyrus ${ }^{24}$, we found the differentially expressed genes to be mainly enriched in glutamatergic excitatory neurons compared to GABAergic and non-neuronal cells, using a Wilcoxon rank test ( $p$-value $=2.2 * 10^{-1} 16$, Figure 3D).

\subsection{Differentially expressed genes in stress network are associated to stress-related diseases}

We hypothesized that the differentially expressed genes in the stress network would be associated to the genetic background of psychiatric disorders, particularly for stress-related brain disorders, as stress plays a major role in the development of these disorders. Using genetic variants from GWAS of the Genomics of Psychiatry Consortium ${ }^{25,26}$, we assessed whether schizophrenia-associated risk loci are enriched in the set of differentially expressed genes. Indeed, schizophrenia risk genes were enriched in the differentially expressed genes in the stress network (Fisher Exact test, BH-adjusted pvalue $=0.015)$. The schizophrenia risk genes CNTN4, GRM3, FUT9, SATB2, GPM6A, COQ10B, DOC2A, and $\mathrm{NISCH}$ were present in our differentially expressed genes, and all except one (COQ10B) were higher expressed in the cortical brain regions vulnerable to stress. Based on a recent GWAS across multiple psychiatric disorder, multiple pleiotropic risk genes were identified. ${ }^{34}$ Furthermore, genedisease associations from DisGeNet, a manually curated database, were used to assess risk gene enrichment for psychiatric, brain and non-brain diseases and non-disease traits. Enrichment was found for neuropsychiatric disorders (schizophrenia, bipolar disorder, and autism spectrum disorder) and other brain diseases (Parkinson's disease). However, no gene enrichment was found for nonbrain diseases (e.g. osteoporosis) and non-disease traits (e.g. height and waste-hip-ratio; Figure 4). Thus, differentially expressed genes in the stress network are predominantly involved in genes relevant for stress-related diseases but not in non-brain-related disorders and traits.

Interestingly, the set of 201 differentially expressed genes in the stress network included a considerable number of receptors. Apart from their use as markers for specific cell types (e.g. ADCYAP1, GABRB1, SSTR1, and TNFRSF12A), these are important for signaling in the brain (e.g. ADCYAP1 modulates glutamatergic signaling ${ }^{35}$ and the HPA-axis response ${ }^{36}$ ) and some of them are 
known to be involved in the regulation of stress. ${ }^{36,37}$ Therefore, we assessed whether there were more receptors in our set of genes associated to psychiatric disorders than you would expect by chance. We found higher odds ratios for brain and psychiatric disorders, with the biggest effect sizes in psychiatric disorders (Figure 4). Effect sizes for receptor enrichment in Epilepsy (p-value $<1 * 10^{-5}$, $\mathrm{OR}=9.07)$, Huntington ( $p$-value $=0.007, \mathrm{OR}=5.18)$, Obsessive Compulsive Disorder ( $p$-value $=0.004$, OR $=7.18)$, Major Depressive Disorder $\left(p\right.$-value $\left.=1 * 10^{-5}, O R=13.5\right)$, Bipolar Disorder $\left(p\right.$-value $=1 * 10^{-}$ $\left.{ }^{5}, \mathrm{OR}=26.8\right)$, and Schizophrenia $(p$-value $=0.03, \mathrm{OR}=3.82)$ were significant.

\subsection{Cortisol sensitivity of the stress network}

The enrichment of the neuronal GO terms in our set of genes and the association with stress-related diseases indicates that the differentially expressed genes in the stress network are relevant for stress and may be responsive to the pivotal stress hormone cortisol. To investigate glucocorticoid sensitivity, we compared our list of differentially expressed genes with genes that show a DNA binding site for the glucocorticoid- and/or mineralocorticoid receptors (GR and $M R$ ) in the rat hippocampus by Chromatin Immunoprecipitation sequencing after stimulation with the endogenous steroid corticosterone. ${ }^{33}$ Differentially expressed genes that showed DNA binding loci for both the GR and MR are: SLC26A4, IGSF11, GRIK4, SCN3B, GABRB1, CCDC85A, KIRREL3, HECW2 and PKIA (9/459 genes with binding sites, $\mathrm{BH}$-adjusted $\mathrm{p}$-value for enrichment $=0.038$ ). There was no significant enrichment for either GR binding (OPRM1, PTER, FUT9, EPB41L4B, PKLR, GPM6A, and GSC; 7/704 genes with binding sites, $\mathrm{BH}$-adjusted $\mathrm{p}$-value $=0.98)$ or MR binding exclusively (ADCYAP1, LAMA1, CNTN4, XPO1, RGS12, MGRN1, CHST15, and ANKLE2; 8/1247 genes with binding sites, BH-adjusted $\mathrm{p}$ value $=0.18$. These results indicate that differentially expressed genes in brain the stress network are enriched for DNA-binding loci of that (in the rat) can be bound by both the GR and the MR.

\section{DISCUSSION}


In this study, we identified genes and pathways in the cortical stress network based on an fMRIbased study involving acute stress exposure. By combining fMRI data to gene expression data, we found 201 differentially expressed genes involved in neuronal processes and enriched in stressrelated psychiatric disorders. Moreover, the enriched genes included several neuropeptides and neurotransmitter receptors with regulation by both the GR and MR and substantial links to HPA-axis activity. This gene set uncovered by combining human gene expression and neuroimaging results give important new insights into the putative neural populations and mechanisms underlying stress vulnerability in humans.

Our results point to the involvement of (cortical) cell type markers in differential stress reactivity. For example, we found enrichment for some astrocyte markers, which among others modulate glutamate metabolism and transmission ${ }^{38}$, and there is evidence from both human and rodent models that they may play a role in stress-related disorders. ${ }^{39}$ Moreover, the differentially expressed genes are in general highly expressed in excitatory glutamatergic compared to inhibitory GABAergic neurons. ${ }^{40}$ Thus, glutamate signaling seems to be involved in a more global level, whereas GABArelated mechanisms that may underlie differential reactivity to stress are limited to a specific subset of GABA-ergic neurons. Specific targeting of these GABAergic populations, based on their receptor repertoire, may help to separate primary from secondary changes in the cortical circuitry.

For genes that do not represent specific neuronal subtypes, changed expression levels may reflect differential responsiveness based on more generic signaling pathways. This may, in particular, be the case for the identified stress-related genes with a genetic association to schizophrenia. OPRM1 encodes for a mu-opioid receptor, which has been shown to interact with glutamate to adapt to chronic drug abuse, a stress-related disorder ${ }^{41}$ Moreover, mu-opioid receptors are known to modulate the HPA-axis. ${ }^{42}$

Genes with high expression levels in the regions vulnerable to stress include neuropeptides and neurotransmitter receptors, which may be directly targeted to modify the activity of these brain 
regions. SST1 codes for the somatostatin receptors, a neuropeptide produced in the hypothalamus. This neuropeptide is known to attenuate the stress response, by counteracting $\mathrm{CRH}$ signaling via the SST1 receptor. ${ }^{43}$ Also a number of serotonergic, GABAergic, and glutamatergic receptors are differentially represented in the stress network. All these factors may well have a role in regulating neuronal network activity during maladaptive stress responses. ${ }^{44-46}$ of note, the excitatory $5-\mathrm{HT} 1 \mathrm{E}$ receptors are overrepresented in brain regions that failed to shut off after stress in at-risk subjects. Antagonism of $5-\mathrm{HT} 2 \mathrm{~A}$ is common between several antipsychotic and antidepressant drugs, and normalizing the activity of these brain regions after stressor exposure may be part of their therapeutic mechanism. However, the exact function of the 5-HT1E receptors are unknown, but HTR1E is a candidate gene for several stress-related disorders. ${ }^{47-49}$

The enrichment analysis of gene ontology terms suggests that the list of differentially expressed genes play a role in stress vulnerability and risk for psychiatric disorders. For example, prenatal chronic stress has consequences on nervous system development as shown in mice ${ }^{50-52}$ Moreover, disruption of neuronal plasticity ${ }^{53}$ is induced by a prolonged stressor and is a common symptoms of stress-related psychiatric disorders. ${ }^{54}$

Furthermore, we found that differentially expressed genes in the stress network are enriched for DNA-binding loci of both the GR and the MR based on experimental data in rats. GR is thought to facilitate recovery and adaptation in the aftermath of stress ${ }^{55}$ and polymorphisms as well as posttranslational modifications alter susceptibility for stress-related psychiatric disorders. ${ }^{56,57}$ The MR has been shown to facilitate stress reactivity. ${ }^{58}$ The link with GR and MR suggests that it related to factors related to systemic adaptations, even though we cannot know to what extent these loci actually reflect target genes.

We found a significant overlap between the genes found to be differentially expressed in the whole stress network and those found to be differentially expressed in the region-specific stress-network analysis of which some are known to be involved in stress-related phenotypes. ${ }^{59,60}$ The differences 
between the results obtained in these experiments can be partially explained by the fact that the AHBA samples were collected using bulk sequencing which does not allow the detection of differences across individual cell populations. ${ }^{61}$ With the increasingly availability of single cell data we will have enough resolution to detect more subtle differences within the cortex, but for now, human brain single cell data is very limited. ${ }^{24,62-64}$ Moreover, previous studies has shown that structures within the cortex are relatively similar in terms of gene expression. ${ }^{14}$ Therefore, the finding of 201 differentially expressed genes, point out to a true difference in the cortical stress-network and all other cortical brain regions. The non-overlapping genes from the combined analysis of cortical and non-cortical samples might be driven by anatomical differences, although it is complex to entangle the true biological signals from anatomy-driven signals.

We do not know whether the differentially expressed genes are subject to genetic regulation and whether they show differential translational responses. Furthermore, we could not infer causality, but rather association of genes with stress-sensitivity. In this regard, it will be of considerable interest to further study the genes that have been linked to psychiatric disorders, as genetic variation may, in fact, lead to abnormal expression of the genes we identified. It will also be of interest to study epigenetic regulation of the genes of interest and gene-environment interactions. ${ }^{65-68}$

Given that we assessed gene expression levels in the healthy brain, it is challenging to interpret the differences in high and low expression levels and the meaning in diseased brains. High expression levels of the genes in the stress network do not necessarily mean that stress sensitivity is a result of the high gene expression per se. It might be the ability to regulate neurobiological processes via direct neurotransmitter and receptor signaling or the ability to indirectly regulate changes in gene expression. ${ }^{69}$ Moreover, we have to take into consideration that we identified genes that already show low baseline expression levels in the brain.

Another limitation of this study is that the low number of samples in some brain regions did not allow the analysis of differential expression within these regions. For example, the precuneus and the 
angular gyrus were underrepresented in the AHBA ( $n=7$ for both regions), but harbored great changes according to the fMRI signal. However, there were sufficient brain samples available from the AHBA to analyze brain regions vulnerable to stress altogether. Moreover, the stress-network we defined was based on 78 males. Given the relatively small sample size, replication in a bigger independent cohort should be awaited. Furthermore, the six donors were five males and one female. It is important to take donor's sex effect into account, since there is a sex difference in the development and symptoms of stress-related diseases ${ }^{70,71}$. Therefore, we checked whether gene expression levels were different for the female donor compared to the male donors. We did not find gender effects of gene expression levels of the differentially expressed genes. To maximize the number of samples, we decided to include the female donor in our analyses. It has to be taken into account, however, that the outcome of the performed task might be different across the genders. ${ }^{72}$ This implies that our results cannot be generalized over the whole population, but are rather reflective for males, since the stress-network we identified could also be male-specific. We also acknowledge that we do not know how the stress network would look like in individuals at risk for other psychiatric disorder. Moreover, brain regions differentially activated by acute stress are specific for the emotion processing task. Therefore, we might have missed some relevant brain structures, and thus genes, that might have become active during another task under stressful conditions. Lastly, the stress network that was used in this paper was based on data from siblings of patients with schizophrenia. Even though stress is a transdiagnostic factor and relevant for all psychiatric disorders ${ }^{73}$, we cannot directly extrapolate the stress network to other psychiatric disorders such as depression and bipolar disorder. There is increasing research into risk groups for these disorders, but to our knowledge, direct comparisons on brain-related stress sensitivity between (risk groups of) across psychiatric disorders are lacking.

To our knowledge, this is the first study to map gene expression atlases to task-based fMRI data in order to identify the molecular mechanisms underlying human stress reactivity in relation to the risk to develop psychiatric disorders. Here, we show that this method can aid in disentangling the 
molecular underpinnings of specific tasks and traits. We showed that genes possibly underlying stress reactivity are also associated with neuronal cell type markers (e.g. glutaminergic excitatory neurons), stress-related disease, GR and MR responsiveness and HPA-axis activity. We identified several neuropeptides and receptors as important players. These identified systems are not only important to understand the underlying mechanisms of stress vulnerability, but can also be used to develop new drug targets. Therefore, identification of novel drug targets involved in stress vulnerability would be of great interest for the development of new therapies in stress-related psychopathology.

\section{FUNDING AND DISCLOSURE}

The authors declare no competing financial interests and have no things to disclose.

\section{ACKNOWLEDGEMENTS}

The authors would like to thank Sjoerd Huisman for his advice and help on some of the statistical aspects of the study and Martijn van den Heuvel for his advice on the manuscript.

\section{REFERENCES}

1. Tost $\mathrm{H}$, Champagne FA, Meyer-Lindenberg A. Environmental influence in the brain, human welfare and mental health. Nat Neurosci 2015; 18(10): 1421-1431.

2. Derijk RH. Single nucleotide polymorphisms related to HPA axis reactivity. Neuroimmunomodulation 2009; 16(5): 340-352.

3. Luque-Garcia A, Teruel-Marti V, Martinez-Bellver S, Adell A, Cervera-Ferri A, Martinez-Ricos J. Neural oscillations in the infralimbic cortex after electrical stimulation of the amygdala. Relevance to acute stress processing. J Comp Neurol 2018; 526(8): 1403-1416.

4. Zhu H, Li Y, Yuan M, Ren Z, Yuan C, Meng Y et al. Increased functional segregation of brain network associated with symptomatology and sustained attention in chronic post-traumatic stress disorder. J Affect Disord 2019; 247: 183-191.

5. Godoy LD, Rossignoli MT, Delfino-Pereira P, Garcia-Cairasco N, de Lima Umeoka EH. A Comprehensive Overview on Stress Neurobiology: Basic Concepts and Clinical Implications. Front Behav Neurosci 2018; 12: 127. 
6. van Oort J, Tendolkar I, Hermans EJ, Mulders PC, Beckmann CF, Schene AH et al. How the brain connects in response to acute stress: $A$ review at the human brain systems level. Neurosci Biobehav Rev 2017; 83: 281-297.

7. van Leeuwen JMC, Vink M, Fernandez G, Hermans EJ, Joels M, Kahn RS et al. At-risk individuals display altered brain activity following stress. Neuropsychopharmacology 2018.

8. Argyropoulos SV, Landau S, Kalidindi S, Toulopoulou T, Castle DJ, Murray RM et al. Twins discordant for schizophrenia: psychopathology of the non-schizophrenic co-twins. Acta Psychiatr Scand 2008; 118(3): 214-219.

9. Romero-Garcia R, Warrier V, Bullmore ET, Baron-Cohen S, Bethlehem RAI. Synaptic and transcriptionally downregulated genes are associated with cortical thickness differences in autism. Mol Psychiatry 2018.

10. Whitaker KJ, Vertes PE, Romero-Garcia R, Vasa F, Moutoussis M, Prabhu G et al. Adolescence is associated with genomically patterned consolidation of the hubs of the human brain connectome. Proc Natl Acad Sci U S A 2016; 113(32): 9105-9110.

11. Ritchie J, Pantazatos SP, French L. Transcriptomic characterization of MRI contrast with focus on the T1-w/T2-w ratio in the cerebral cortex. Neuroimage 2018; 174: 504-517.

12. McColgan P, Gregory S, Seunarine KK, Razi A, Papoutsi M, Johnson E et al. Brain Regions Showing White Matter Loss in Huntington's Disease Are Enriched for Synaptic and Metabolic Genes. Biol Psychiatry 2018; 83(5): 456-465.

13. Vertes PE, Rittman T, Whitaker KJ, Romero-Garcia R, Vasa F, Kitzbichler MG et al. Gene transcription profiles associated with inter-modular hubs and connection distance in human functional magnetic resonance imaging networks. Philos Trans R Soc Lond B Biol Sci 2016; 371(1705).

14. Hawrylycz M, Miller JA, Menon V, Feng D, Dolbeare T, Guillozet-Bongaarts AL et al. Canonical genetic signatures of the adult human brain. Nat Neurosci 2015; 18(12): 1832-1844.

15. Romme IA, de Reus MA, Ophoff RA, Kahn RS, van den Heuvel MP. Connectome Disconnectivity and Cortical Gene Expression in Patients With Schizophrenia. Biol Psychiatry 2017; 81(6): 495-502.

16. Kirschbaum C, Pirke KM, Hellhammer DH. The 'Trier Social Stress Test'--a tool for investigating psychobiological stress responses in a laboratory setting. Neuropsychobiology 1993; 28(1-2): 76-81.

17. P.J. Lang MMB, B.N, Cuthbert. International Affective Picture System (IAPS) Technical Manual and Affective Rating NIMH Center for the Study of Emotion and Attention, University of Florida, Gainesville, FL 1997. 
18. Hawrylycz MJ, Lein ES, Guillozet-Bongaarts AL, Shen EH, Ng L, Miller JA et al. An anatomically comprehensive atlas of the adult human brain transcriptome. Nature 2012; 489(7416): 391399.

19. Keo A, Aziz NA, Dzyubachyk O, van der Grond J, van Roon-Mom WMC, Lelieveldt BPF et al. Co-expression Patterns between ATN1 and ATXN2 Coincide with Brain Regions Affected in Huntington's Disease. Front Mol Neurosci 2017; 10: 399.

20. Huisman SMH, van Lew B, Mahfouz A, Pezzotti N, Hollt T, Michielsen Let al. BrainScope: interactive visual exploration of the spatial and temporal human brain transcriptome. Nucleic Acids Res 2017; 45(10): e83.

21. Eden E, Navon R, Steinfeld I, Lipson D, Yakhini Z. GOrilla: a tool for discovery and visualization of enriched GO terms in ranked gene lists. BMC Bioinformatics 2009; 10: 48.

22. Zhang Y, Chen K, Sloan SA, Bennett ML, Scholze AR, O'Keeffe S et al. An RNA-sequencing transcriptome and splicing database of glia, neurons, and vascular cells of the cerebral cortex. J Neurosci 2014; 34(36): 11929-11947.

23. Mancarci BO, Toker L, Tripathy SJ, Li B, Rocco B, Sibille E et al. Cross-Laboratory Analysis of Brain Cell Type Transcriptomes with Applications to Interpretation of Bulk Tissue Data. eNeuro 2017; 4(6).

24. Hodge RD, Bakken TE, Miller JA, Smith KA, Barkan ER, Graybuck LT et al. Conserved cell types with divergent features in human versus mouse cortex. Nature 2019.

25. Schizophrenia Working Group of the Psychiatric Genomics C. Biological insights from 108 schizophrenia-associated genetic loci. Nature 2014; 511(7510): 421-427.

26. Pardinas AF, Holmans P, Pocklington AJ, Escott-Price V, Ripke S, Carrera N et al. Common schizophrenia alleles are enriched in mutation-intolerant genes and in regions under strong background selection. Nat Genet 2018; 50(3): 381-389.

27. Pinero J, Bravo A, Queralt-Rosinach N, Gutierrez-Sacristan A, Deu-Pons J, Centeno E et al. DisGeNET: a comprehensive platform integrating information on human disease-associated genes and variants. Nucleic Acids Res 2017; 45(D1): D833-D839.

28. Lin YJ, Liao WL, Wang CH, Tsai LP, Tang CH, Chen $\mathrm{CH}$ et al. Association of human heightrelated genetic variants with familial short stature in Han Chinese in Taiwan. Sci Rep 2017; 7(1): 6372 .

29. Heid IM, Jackson AU, Randall JC, Winkler TW, Qi L, Steinthorsdottir V et al. Meta-analysis identifies 13 new loci associated with waist-hip ratio and reveals sexual dimorphism in the genetic basis of fat distribution. Nat Genet 2010; 42 (11): 949-960. 
30. Stahl EA, Breen G, Forstner AJ, McQuillin A, Ripke S, Trubetskoy V et al. Genome-wide association study identifies 30 loci associated with bipolar disorder. Nat Genet 2019; 51(5): 793-803.

31. Wray NR, Ripke S, Mattheisen M, Trzaskowski M, Byrne EM, Abdellaoui A et al. Genome-wide association analyses identify 44 risk variants and refine the genetic architecture of major depression. Nat Genet 2018; 50(5): 668-681.

32. Wang $\mathrm{Y}$, Wang $\mathrm{M}$, Yin S, Jang R, Wang J, Xue Z et al. NeuroPep: a comprehensive resource of neuropeptides. Database (Oxford) 2015; 2015: bav038.

33. van Weert L, Buurstede JC, Mahfouz A, Braakhuis PSM, Polman JAE, Sips HCM et al. NeuroD Factors Discriminate Mineralocorticoid From Glucocorticoid Receptor DNA Binding in the Male Rat Brain. Endocrinology 2017; 158(5): 1511-1522.

34. Consortium C-DWGotPG. Genome wide meta-analysis identifies genomic relationships, novel loci, and pleiotropic mechanisms across eight psychiatric disorders. BioRxiv 2019.

35. Magistretti PJ, Cardinaux JR, Martin JL. VIP and PACAP in the CNS: regulators of glial energy metabolism and modulators of glutamatergic signaling. Ann N Y Acad Sci 1998; 865: 213-225.

36. Stroth $\mathrm{N}$, Holighaus $\mathrm{Y}$, Ait-Ali D, Eiden LE. PACAP: a master regulator of neuroendocrine stress circuits and the cellular stress response. Ann N Y Acad Sci 2011; 1220: 49-59.

37. Giordano R, Picu A, Bonelli L, Balbo M, Berardelli R, Marinazzo E et al. Hypothalamuspituitary-adrenal axis evaluation in patients with hypothalamo-pituitary disorders: comparison of different provocative tests. Clin Endocrinol (Oxf) 2008; 68(6): 935-941.

38. Mei YY, Wu DC, Zhou N. Astrocytic Regulation of Glutamate Transmission in Schizophrenia. Front Psychiatry 2018; 9: 544.

39. Murphy-Royal C, Gordon GR, Bains IS. Stress-induced structural and functional modifications of astrocytes-Further implicating glia in the central response to stress. Glia 2019; 67(10): 1806-1820.

40. Rebecca D Hodge TEB, Jeremy A Miller, Kimberly A Smith, Eliza R Barkan, Lucas T Graybuck, Jennie L Close, Brian Long, Osnat Penn, Zizhen Yao, Jeroen Eggermont, Thomas Hollt, Boaz P Levi, Soraya I Shehata, Brian Aevermann, Allison Beller, Darren Bertagnolli, Krissy Brouner, Tamara Casper, Charles Cobbs, Rachel Dalley, Nick Dee, Song-Lin Ding, Richard G Ellenbogen, Olivia Fong, Emma Garren, Jeff Goldy, Ryder P Gwinn, Daniel Hirschstein, C Dirk Keene, Mohamed Keshk, Andrew L Ko, Kanan Lathia, Ahmed Mahfouz, Zoe Maltzer, Medea McGraw, Thuc Nghi Nguyen, Julie Nyhus, Jeffrey G Ojemann, Aaron Oldre, Sheana Parry, Shannon Reynolds, Christine Rimorin, Nadiya V Shapovalova, Saroja Somasundaram, Aaron Szafer, Elliot R Thomsen, Michael Tieu, Richard H Scheuermann, Rafael Yuste, Susan M Sunkin, Boudewijn Lelieveldt, David Feng, Lydia Ng, Amy Bernard, Michael Hawrylycz, John Phillips, 
Bosiljka Tasic, Hongkui Zeng, Allan R Jones, Christof Koch, Ed S Lein. Conserved cell types with divergent features between human and mouse cortex. BioRxiv 2018.

41. Scavone JL, Asan E, Van Bockstaele EJ. Unraveling glutamate-opioid receptor interactions using high-resolution electron microscopy: implications for addiction-related processes. Exp Neurol 2011; 229(2): 207-213.

42. degli Uberti EC, Petraglia F, Bondanelli M, Guo AL, Valentini A, Salvadori S et al. Involvement of mu-opioid receptors in the modulation of pituitary-adrenal axis in normal and stressed rats. J Endocrinol Invest 1995; 18(1): 1-7.

43. Stengel A, Tache YF. Activation of Brain Somatostatin Signaling Suppresses CRF ReceptorMediated Stress Response. Front Neurosci 2017; 11: 231.

44. Krishnan V. Defeating the fear: new insights into the neurobiology of stress susceptibility. Exp Neurol 2014; 261: 412-416.

45. Picciotto MR, Higley MJ, Mineur YS. Acetylcholine as a neuromodulator: cholinergic signaling shapes nervous system function and behavior. Neuron 2012; 76(1): 116-129.

46. Mineur YS, Obayemi A, Wigestrand MB, Fote GM, Calarco CA, Li AM et al. Cholinergic signaling in the hippocampus regulates social stress resilience and anxiety- and depressionlike behavior. Proc Natl Acad Sci U S A 2013; 110(9): 3573-3578.

47. Sener EF, Taheri S, Sahin MC, Bayramov KK, Marasli MK, Zararsiz G et al. Altered Global mRNA Expressions of Pain and Aggression Related Genes in the Blood of Children with Autism Spectrum Disorders. J Mol Neurosci 2019; 67(1): 89-96.

48. Nishioka M, Bundo M, Koike S, Takizawa R, Kakiuchi C, Araki T et al. Comprehensive DNA methylation analysis of peripheral blood cells derived from patients with first-episode schizophrenia. J Hum Genet 2013; 58(2): 91-97.

49. Baca-Garcia E, Vaquero-Lorenzo C, Perez-Rodriguez MM, Gratacos M, Bayes M, SantiagoMozos $R$ et al. Nucleotide variation in central nervous system genes among male suicide attempters. Am J Med Genet B Neuropsychiatr Genet 2010; 153B(1): 208-213.

50. Giordana LN, Bozzo AA, Cots DS, Monedero Cobeta I, Rolando A, Borghi D et al. The effect of chronic stress on prenatal development of the central nervous system. Biotech Histochem 2015; 90(2): 146-151.

51. Miranda A, Sousa N. Maternal hormonal milieu influence on fetal brain development. Brain Behav 2018; 8(2): e00920. 
52. Entringer S, Buss C, Wadhwa PD. Prenatal stress, development, health and disease risk: A psychobiological perspective-2015 Curt Richter Award Paper. Psychoneuroendocrinology 2015; 62: 366-375.

53. Christoffel DJ, Golden SA, Russo SJ. Structural and synaptic plasticity in stress-related disorders. Rev Neurosci 2011; 22(5): 535-549.

54. Etkin A, Gyurak A, O'Hara R. A neurobiological approach to the cognitive deficits of psychiatric disorders. Dialogues Clin Neurosci 2013; 15(4): 419-429.

55. Joels M, Sarabdjitsingh RA, Karst H. Unraveling the time domains of corticosteroid hormone influences on brain activity: rapid, slow, and chronic modes. Pharmacol Rev 2012; 64(4): 901938.

56. Spijker AT, van Rossum EF. Glucocorticoid receptor polymorphisms in major depression. Focus on glucocorticoid sensitivity and neurocognitive functioning. Ann N Y Acad Sci 2009; 1179: 199-215.

57. McClung CA. Glucocorticoid receptor function and resilience: a tale of mice and men. Biol Psychiatry 2015; 77(4): 310-311.

58. ter Heegde F, De Rijk RH, Vinkers $\mathrm{CH}$. The brain mineralocorticoid receptor and stress resilience. Psychone uroendocrinology 2015; 52: 92-110.

59. Wojcik SM, Tantra M, Stepniak B, Man KN, Muller-Ribbe K, Begemann M et al. Genetic markers of a Munc13 protein family member, BAIAP3, are gender specifically associated with anxiety and benzodiazepine abuse in mice and humans. Mol Med 2013; 19: 135-148.

60. Savarese A, Lasek AW. Regulation of anxiety-like behavior and Crhr1 expression in the basolateral amygdala by LMO3. Psychoneuroendocrinology 2018; 92: 13-20.

61. Tasic B, Yao Z, Graybuck LT, Smith KA, Nguyen TN, Bertagnolli D et al. Shared and distinct transcriptomic cell types across neocortical areas. Nature 2018; 563(7729): 72-78.

62. Lake BB, Chen S, Sos BC, Fan J, Kaeser GE, Yung YC et al. Integrative single-cell analysis of transcriptional and epigenetic states in the human adult brain. Nat Biotechnol 2018; 36(1): 70-80.

63. Habib N, Avraham-Davidi I, Basu A, Burks T, Shekhar K, Hofree M et al. Massively parallel single-nucleus RNA-seq with DroNc-seq. Nat Methods 2017; 14(10): 955-958.

64. Darmanis S, Sloan SA, Zhang Y, Enge M, Caneda C, Shuer LM et al. A survey of human brain transcriptome diversity at the single cell level. Proc Natl Acad Sci U S A 2015; 112(23): 72857290 . 
65. Vinkers CH, Kalafateli AL, Rutten BP, Kas MJ, Kaminsky Z, Turner JD et al. Traumatic stress and human DNA methylation: a critical review. Epigenomics 2015; 7(4): 593-608.

66. Zovkic IB, Meadows JP, Kaas GA, Sweatt JD. Interindividual Variability in Stress Susceptibility: A Role for Epigenetic Mechanisms in PTSD. Front Psychiatry 2013; 4: 60.

67. Stankiewicz AM, Swiergiel AH, Lisowski P. Epigenetics of stress adaptations in the brain. Brain Res Bull 2013; 98: 76-92.

68. Klengel T, Binder EB. Epigenetics of Stress-Related Psychiatric Disorders and Gene $\mathrm{x}$ Environment Interactions. Neuron 2015; 86(6): 1343-1357.

69. Krishnan V, Han MH, Graham DL, Berton O, Renthal W, Russo SJ et al. Molecular adaptations underlying susceptibility and resistance to social defeat in brain reward regions. Cell 2007; 131(2): 391-404.

70. Riecher-Rossler A. Sex and gender differences in mental disorders. Lancet Psychiatry 2017; 4(1): 8-9.

71. Bangasser DA, Eck SR, Telenson AM, Salvatore M. Sex differences in stress regulation of arousal and cognition. Physiol Behav 2018; 187: 42-50.

72. Kret ME, De Gelder B. A review on sex differences in processing emotional signals. Neuropsychologia 2012; 50(7): 1211-1221.

73. Zorn JV, Schur RR, Boks MP, Kahn RS, Joels M, Vinkers CH. Cortisol stress reactivity across psychiatric disorders: A systematic review and meta-analysis. Psychoneuroendocrinology 2017; 77: 25-36. 


\section{FIGURES / LEGENDS}

Table 1 Group characteristics of fMRI study

\begin{tabular}{l|lllll} 
& Con-no-stress & Con-stress & Sib-no-stress & Sib-stress & p-value \\
\hline $\mathbf{N}$ & 19 & 20 & 20 & 19 & \\
Age (years) & $32.6(8.5)$ & $34.8(9.1)$ & $33.8(10.8)$ & $32.5(7.4)$ & $0.836^{\mathrm{a}}$ \\
Handedness (\% right) & 89.5 & 95 & 70 & 89.5 & $0.194^{\mathrm{b}}$ \\
Educational level & $7.6(2.7)$ & $7.1(1.9)$ & $7.0(1.6)$ & $7.4(1.5)$ & $0.688^{\mathrm{a}}$ \\
Body Mass Index & $24.1(2.7)$ & $24.2(2.1)$ & $24.0(3.0)$ & $24.9(3.9)$ & $0.774^{\mathrm{a}}$ \\
Ethnicity (\% Caucasian) & 84.2 & 90 & 90 & 84.2 & $0.900^{\mathrm{b}}$ \\
Smoker (\% yes) & 5.3 & 35 & 30 & 31.6 & $0.132^{\mathrm{b}}$
\end{tabular}

Con = control; sib $=$ sibling of schizophrenia patients.

Mean values (SD) are denoted for age, education, and body mass index. All other values are reported in frequency.

$\mathrm{a}=$ one-way-ANOVA

$b=$ chi square test 


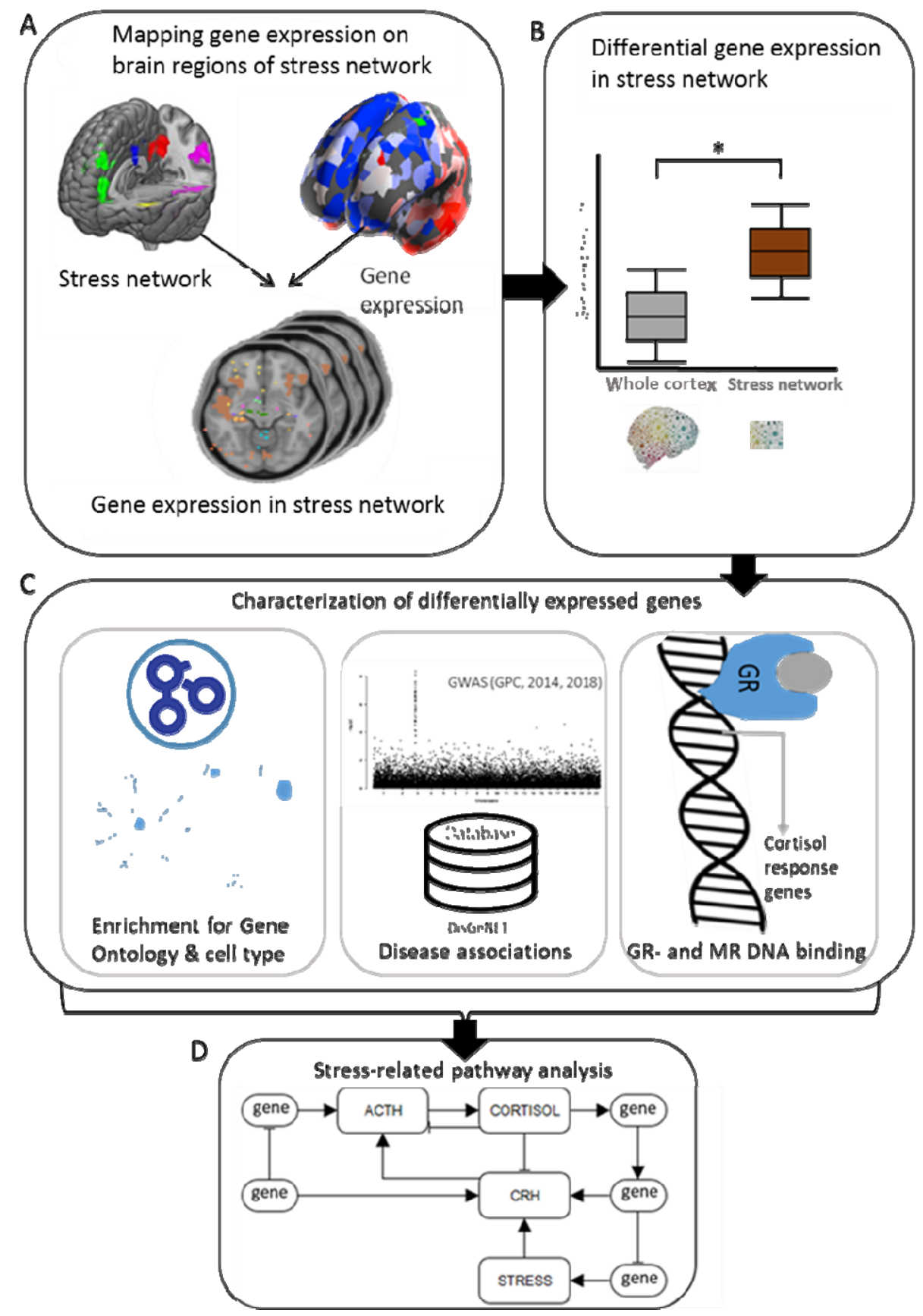

Figure 1 Study overview. (A) Cortical brain regions vulnerable to stress (= stress network) during an emotion processing task were assessed in an fMRI study. All brain regions showed higher stressinduced brain activity following an acute social stressor in at risk individuals (healthy siblings of schizophrenia patients). The fMRI data was mapped to the AHBA resulting in an overlay of the fMRI and gene expression data. (B) With this overlay, differential gene expression between the brain regions vulnerable to stress and the rest of the cortex were assessed. (C) Differentially expressed genes were consequently characterized by identifying enrichment for gene ontology and cell type 
bioRxiv preprint doi: https://doi.org/10.1101/661587; this version posted June 12, 2020. The copyright holder for this preprint (which was not certified by peer review) is the author/funder, who has granted bioRxiv a license to display the preprint in perpetuity. It is made available under aCC-BY-NC 4.0 International license.

markers, associations with stress-related diseases and enrichment for cortisol responsive genes. (D) Information provided by the previous analyses was used to build a model of a molecular pathway underlying human stress reactivity. 
A

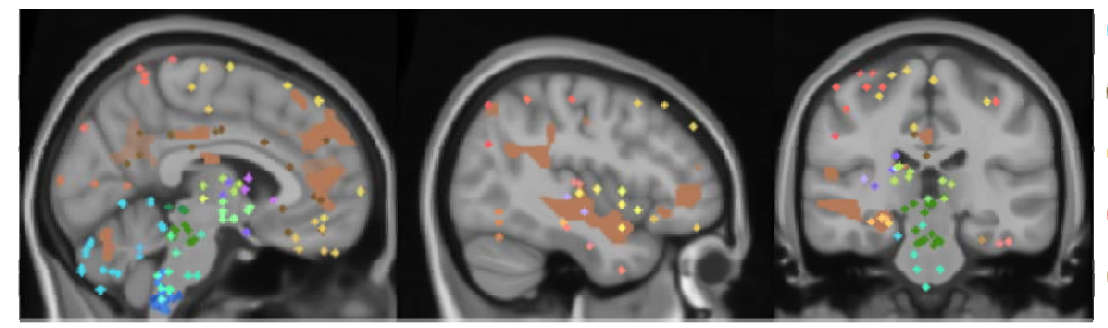

Cerebellum Cingulate gyrus Frontal gyrus Temporal gyrus Hippocampus

B

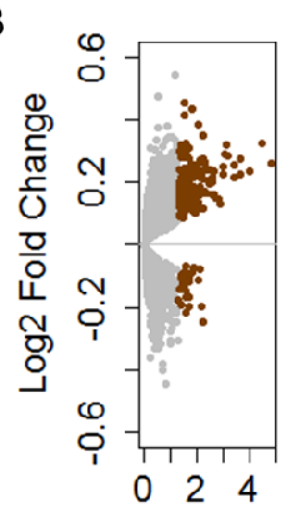
$-\log 10(p-v a l u e)$
C

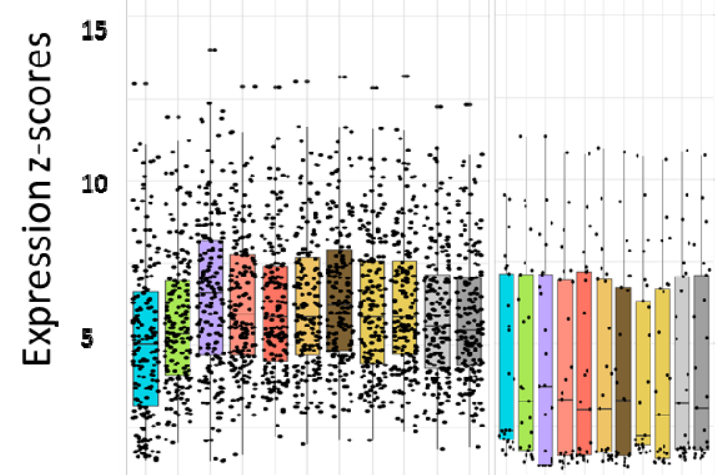

Whole brain

Cerebrum

VIPFCL

由 VIPFCR

MCC

Hippocampus+ TG

Precuneus + ACC

MTG + STG

Claustrum

Lateral thalamus

Cerebellar vermis

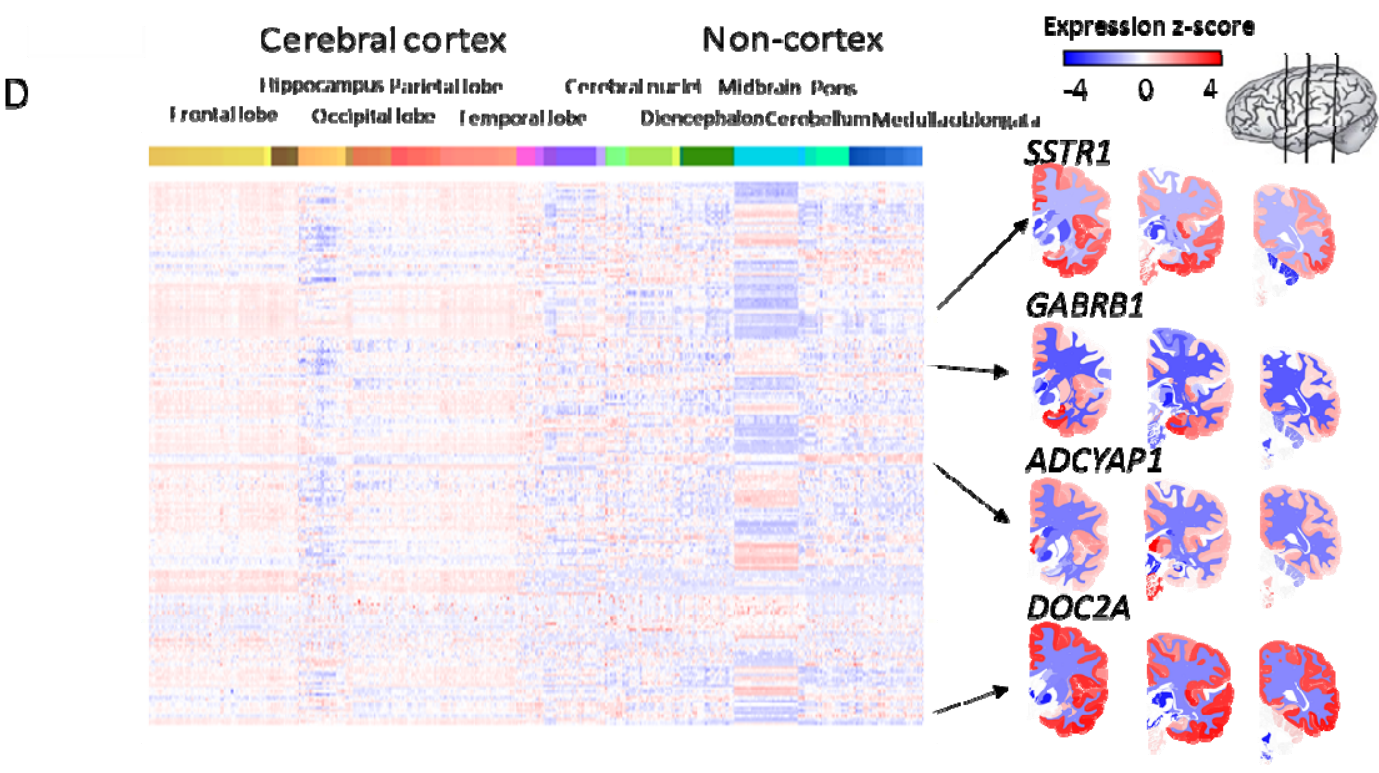

Figure 2 Differentially expressed genes in brain regions vulnerable to stress can be identified using gene expression atlases. (A) Brain regions in the stress network are present throughout the brain (including cerebellum, cingulate gyrus, frontal gyrus, temporal gyrus, and hippocampal formation). For the analysis, all regions in the cortex were combined. (B) Differential gene expression was determined for the cortical stress network compared to the rest of the cortex. Significant genes (BHadjusted $p$-value $<0.05$ have higher expression in the stress network. Grey dots represent nonsignificant genes and brown dots represent significant genes based on meta-analysis across all six AHBA donors. (C) The box plots show the expression of the higher (left) and lower (right) expressed 
genes compared to the rest of the cortex in the brain regions of interest from the stress network. (D) In the whole brain, differentially expressed genes show mostly high expression levels in the cortex and low expression levels in non-cortical brain regions. In the heatmap, each row represents a gene and each column represents a sample and all samples of the AHBA are illustrated here. On the right, coronal brain sections for the genes SSTR1, GABRB1, ADCYAP1, and DOC2A are presented. Colors indicates high (red) and low (blue) expression levels. 

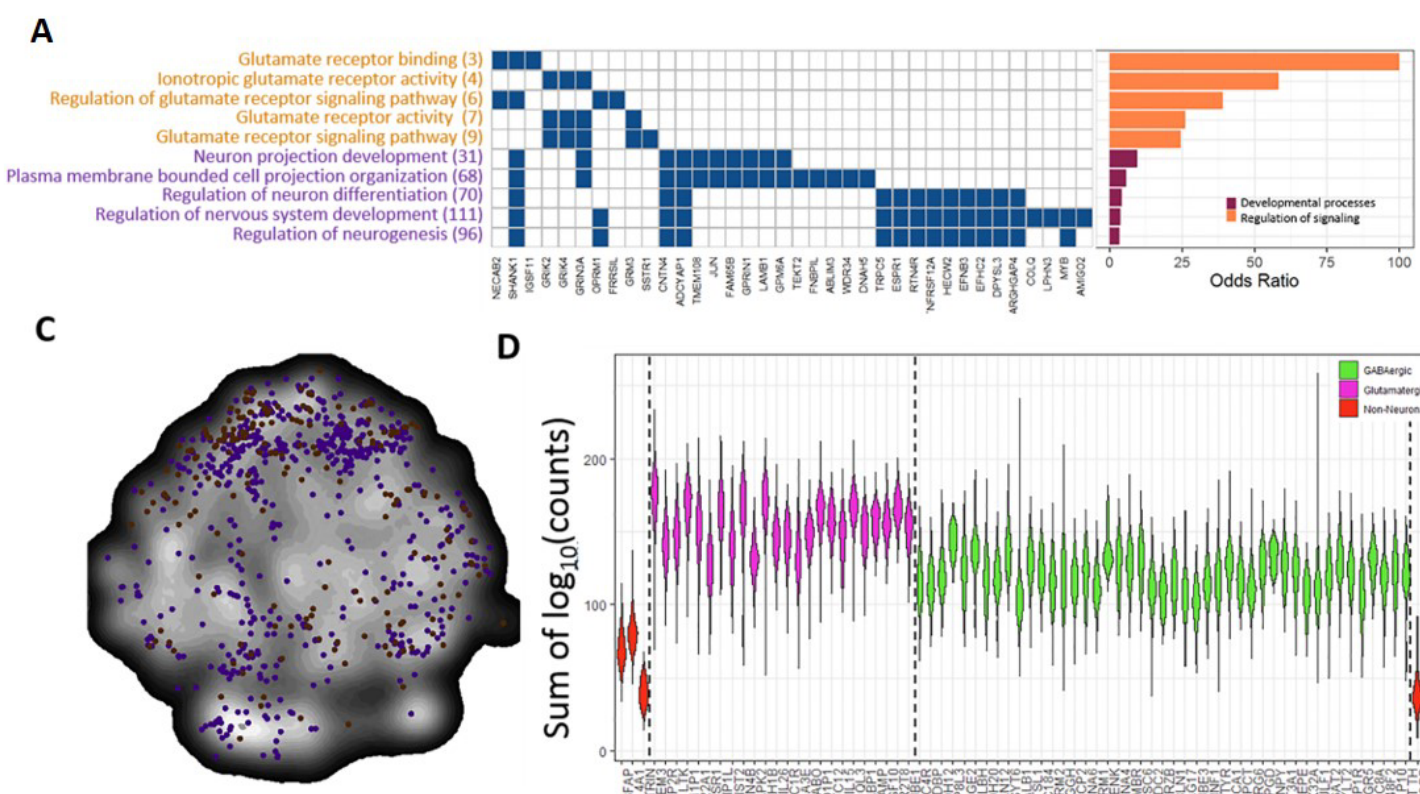

D

Figure 3 Functionality of differentially expressed genes in the stress network. (A) Differentially expressed genes annotated to one of the GO terms were assigned to multiple GO terms and thus involved in multiple processes. Between parenthesis, the total number of genes assigned to the GO term is depicted. On the right side of the graph, ORs are displayed per GO term. (B) Differentially expressed genes (brown), neuronal marker genes (purple) and overlapping genes (yellow) are plotted in a t-SNE plot generated using BrainScope. $\mathrm{nl}^{20}$, where points close together represent genes with similar gene expression profiles. The differentially expressed genes show a similar profile in the t-SNE plot as neuronal cell markers (purple). (C) ORs for different neuronal subtypes. ORs were considered significant when the $\mathrm{BH}$-adjusted p-value $<0.05\left({ }^{*}\right)$. Neuronal subtypes without a marker represented in the differentially expressed genes are not illustrated in the graph. (D) The sum of the $\log _{10}$ values of the counts per gene is plotted for each cell cluster. Green clusters belong to GABAergic cells, purple clusters to glutamatergic cells and red clusters to non-neuronal cells. 
bioRxiv preprint doi: https://doi.org/10.1101/661587; this version posted June 12,2020 . The copyright holder for this preprint (which was not certified by peer review) is the author/funder, who has granted bioRxiv a license to display the preprint in perpetuity. It is made available under aCC-BY-NC 4.0 International license.

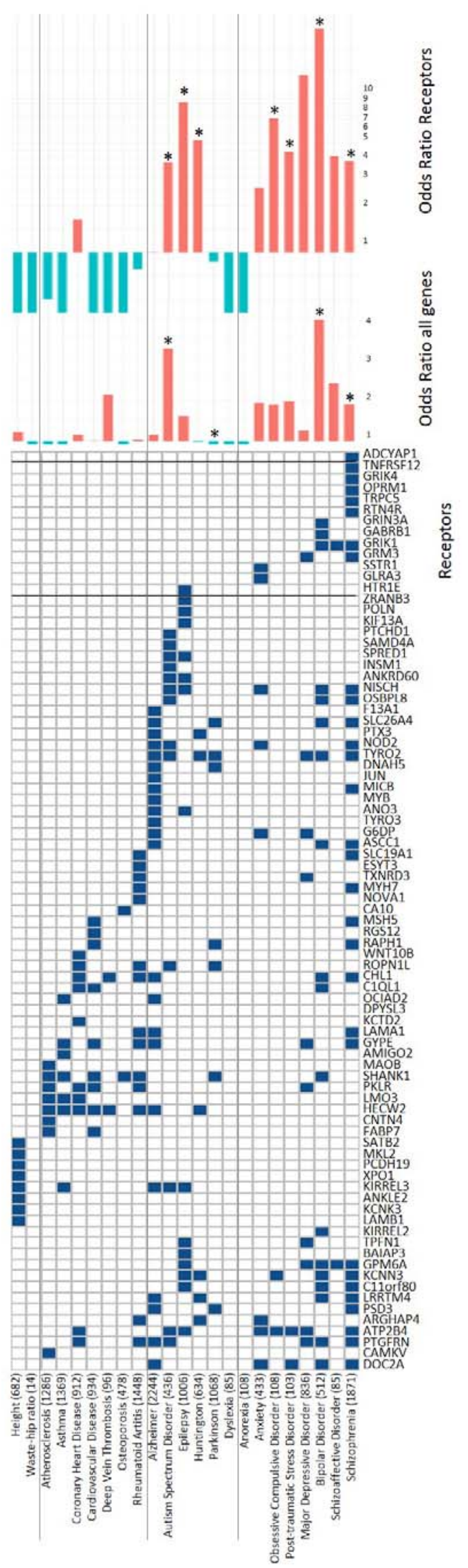


Figure 4 Differentially expressed genes in the stress network and stress-related psychiatric

disorders Disease risk gene enrichment was performed for the differentially expressed genes. The diseases are clustered as non-brain related disease, brain disease and psychiatric disease. As a nonedisease-associated set of genes, waste-hip ratio and height were used. Numbers between the parenthesis indicate the number of genes known to be associated with the disease, based on DisGeNet. The effect size of the gene enrichment is presented at the middle part of the figure and considered significant when the $\mathrm{BH}$-adjusted $\mathrm{p}$-value $<0.05\left({ }^{*}\right)$. Blue bars mean depletion of genes, whereas red bars indicate enrichment of genes in a trait. ORs for the amount of receptors in the set of differentially expressed genes are depicted for every trait (shown on the right side of the graph). 


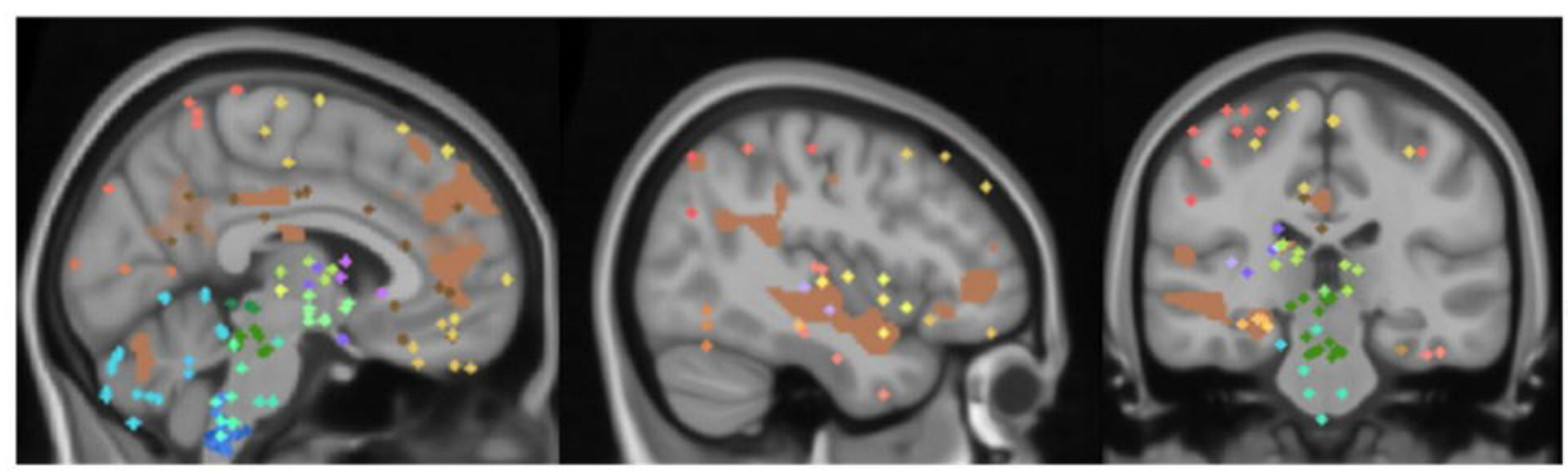

Cerebellum

Cingulate gyrus

Frontal gyrus

Temporal gyrus

Hippocampus

B

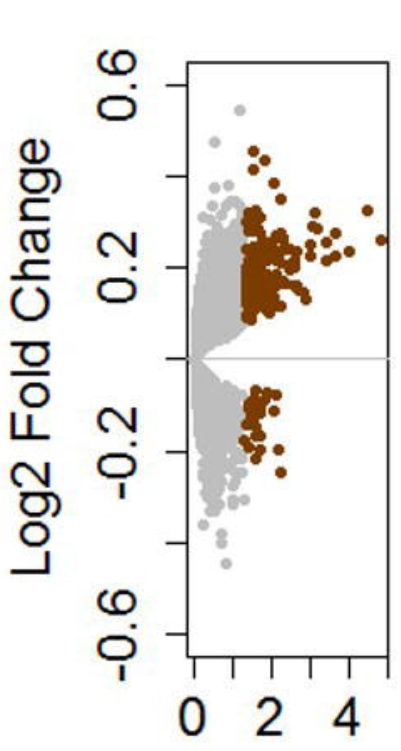

C

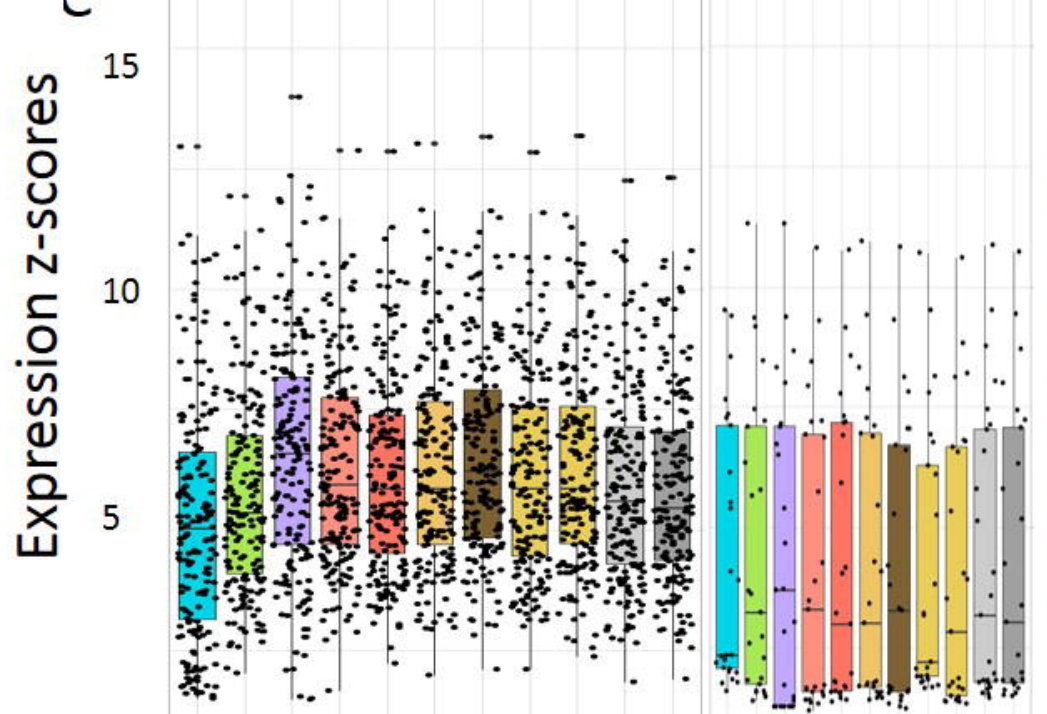

Whole brain

Cerebrum

vIPFC L

VIPFC R

MCC

Hippocampus + TG

Precuneus + ACC

MTG + STG

Claustrum

Lateral thalamus

Cerebellar vermis

- $\log 10(p-$ value $)$

Higher expression in mask

Lower expression in mask

\section{Cerebral cortex Non-cortex}

D

Hippocampus Parietal lobe

Cerebral nuclei Midbrain Pons

Frontal lobe Occipital lobe Temporal lobe DiencephaloncerebellumMedullaoblongata

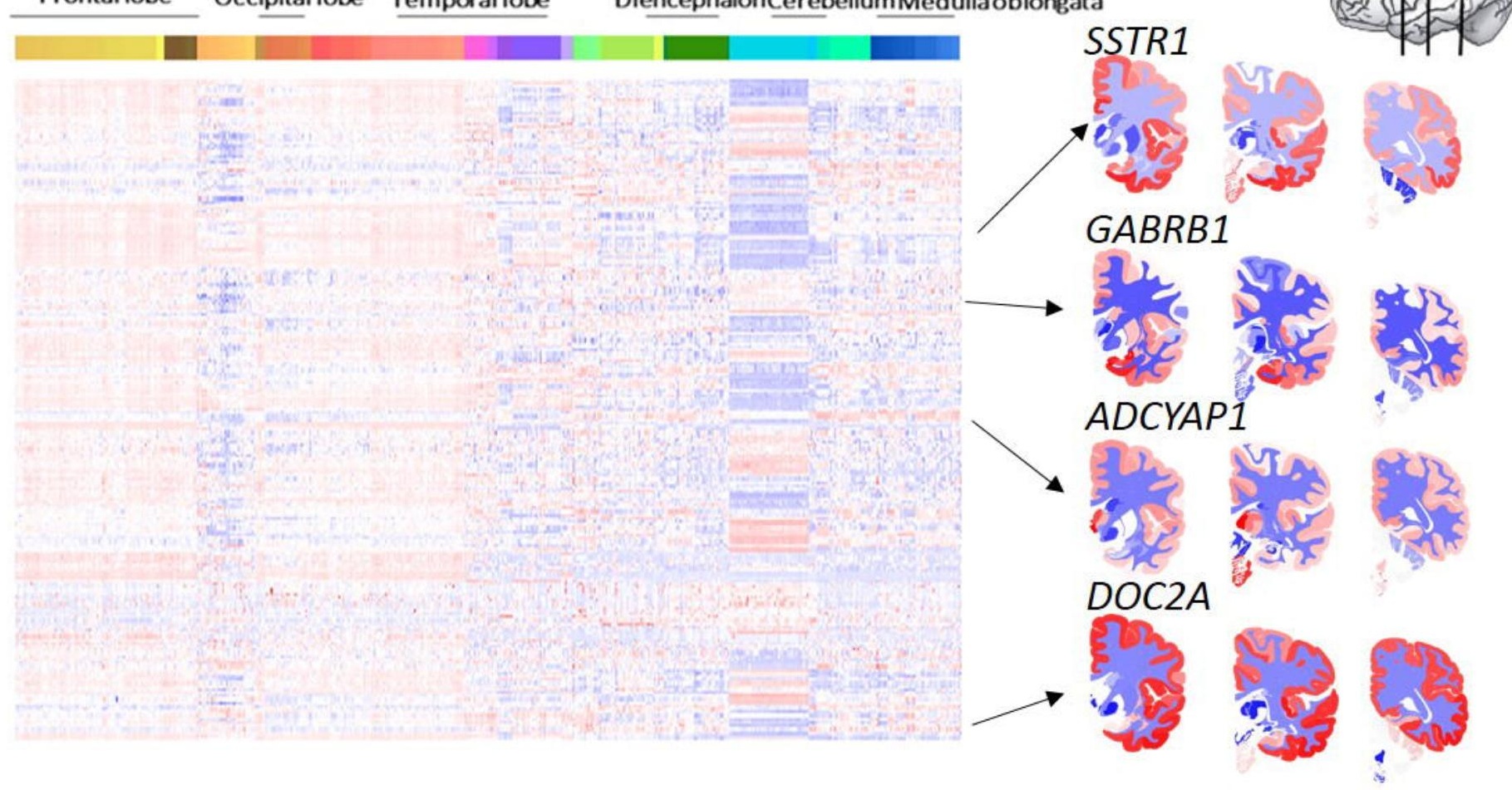




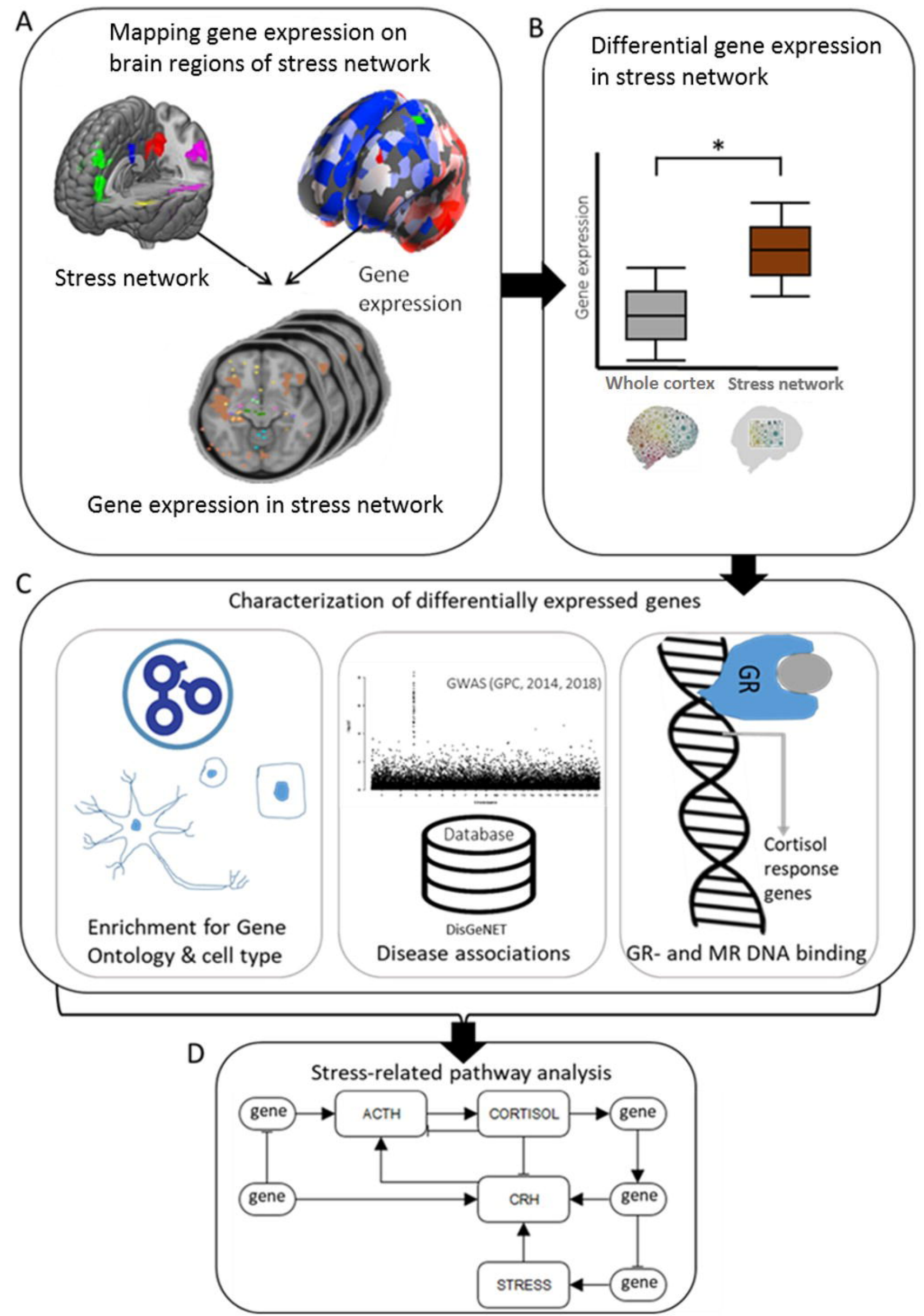




\section{A}

Glutamate receptor binding (3)

Ionotropic glutamate receptor activity (4)

Regulation of glutamate receptor signaling pathway (6) Glutamate receptor activity (7)

Glutamate receptor signaling pathway (9)

Neuron projection development (31)

Plasma membrane bounded cell projection organization (68)

Regulation of neuron differentiation (70)

Regulation of nervous system development (111)

Regulation of neurogenesis (96)

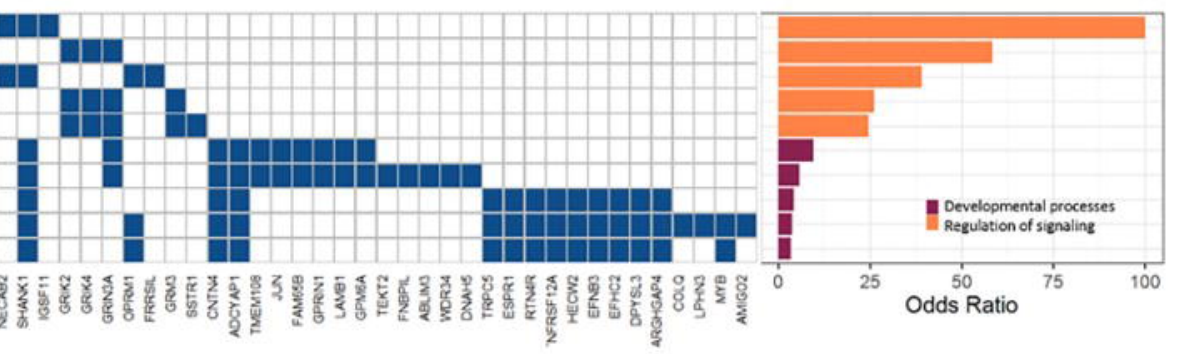

C
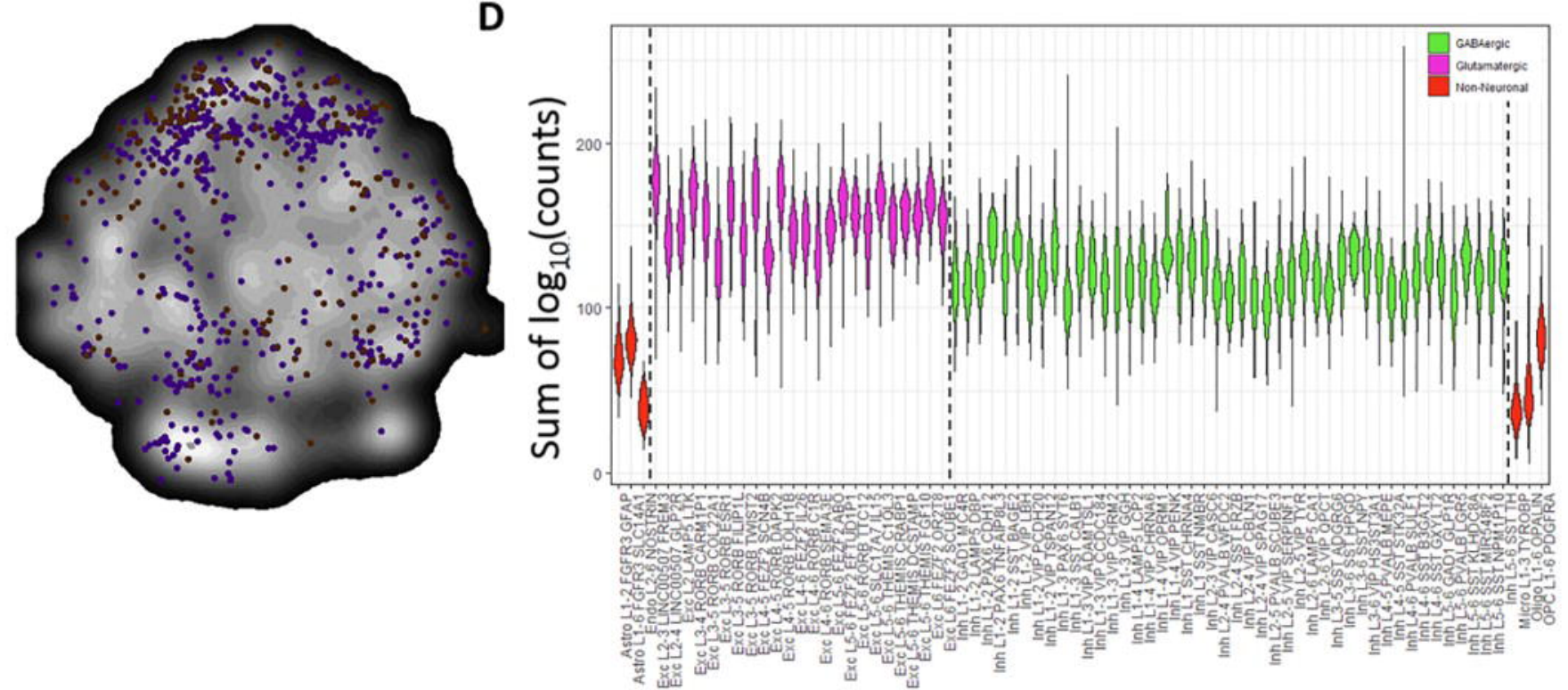